

\title{
El río reflejo de Medellín: cambios en la concepción de un espacio según la época ${ }^{1}$
}

\author{
The river reflection of Medellín: changes in the \\ conception of a space according to the time
}

Cómo citar:

Castro Valencia, I., Guerra Giraldo, P., \& Loaiza García, L. F. (2017). El río reflejo de Medellín: cambios en la concepción de un espacio según la época. Designia, 4(2), 107-125.

\section{${ }^{1}$ Artículo resultado del trabajo investigativo realizado durante tres semestres en la línea de cultura material de la Facultad de Diseño Industrial de la Universidad Pontificia Bolivariana de Medellín. Las autoras expresan sus agradecimientos a Miguel Arango y Marcela Ceballos, asesores del proyecto. \\ *Diseñadoras Industriales de la Universidad Pontificia Bolivariana de Medellín con interés investigativo en cultura material. isabel.castro@upb.edu.co; paulina.guerra@upb.edu.co; luisa.loaiza@upb.edu.co}

Palabras clave:

Río Medellín, representaciones sociales, usos, prácticas, apropiación.

Key words:

Medellin river, social representations, uses, practices, appropriation.

Recibido: 22/03/2016

Aceptado: 19/10/2016

\section{Resumen:}

Este artículo presenta los resultados de una investigación que buscó entender cómo ha cambiado, para los habitantes de Medellín, el significado del río de su ciudad, desde finales del siglo XIX hasta principios del XXI. Mediante un esquema conceptual fue posible estudiar distintas representaciones sociales de las personas, evidenciadas en prácticas y apropiaciones asociadas con el afluente a lo largo de tres épocas, que fueron denominadas preindustrial, industrial y postindustrial. El río ha sido considerado un referente en determinados momentos y en otros ha pasado a un total olvido. Su interacción con la ciudad ha estado permeada por el ideal de progreso de los dirigentes pertenecientes a la élite de cada época, lo cual ha influido en él de diversas maneras y ha generado repercusiones económicas, sociales, ambientales e infraestructurales. 


\section{Abstract:}

This paper is derived from research aiming to analyze how the river in Medellín has had different meanings for this city's inhabitants, since late 19th century until early 21st century. It was possible to study distinct social representations which have shaped practices and appropriations linked to the river throughout three periods (pre-industrial, industrial, post-industrial). The interaction of this element with the city has been influenced by each period elite's idea of progress, being considered an important resource or being totally neglected. These changes have caused both negative and positive impacts on the urban context, generating economic, social, environmental and infrastructural effects.

\section{INTRODUCCIÓN}

En Medellín, la capital del departamento colombiano de Antioquia, se encuentra un río ignorado por la mayoría de la población pero que también representa un referente, el cual es objeto de particulares relaciones con los habitantes. Para la investigación aquí presentada surgió el interés por profundizar en esas relaciones, sus cambios e implicaciones, en un periodo comprendido entre finales del siglo XIX y principios del XXI.

En el siglo XIX el afluente funcionaba como medio de transporte y daba un gran impulso al comercio, pues a través de él se desplazaban mercancías y materiales de construcción, además de utilizarse para la extracción de arena, la pesca y el baño como actividad recreativa. Con el paso de los años esta relación fue cambiando de manera cada vez más radical a medida que el río se canalizó para permitir la expansión poblacional. Se le dejó entonces a un lado, se volvió ajeno y las prácticas antes realizadas dejaron de ser compatibles con las costumbres traídas por la tecnología emergente en materia de transporte y urbanización. Cuando creció la economía y se ingresó a la industrialización, el río se desvalorizó, se esquivó y se contaminó, apareció una barrera tanto física como mental para interactuar con él y se convirtió en la cloaca de Medellín (Betancur, 2012). Lo natural fue apartado para avanzar con el desarrollo urbanístico y de infraestructura, lo que también generó desigualdad social y económica en la urbe. 
Con las intervenciones infraestructurales, las calzadas paralelas a la canalización se consolidaron como las vías más importantes para facilitar la conexión sur-norte y mejorar la movilidad de los vehículos automotores. Cuanto más crecía la ciudad en términos industriales y poblacionales, mayor era la cantidad de desechos producidos y arrojados al río, razón por la cual a principios de los años noventa surgió una preocupación por tomar medidas para revertir esta situación. Tal iniciativa fue motivada por corrientes internacionales que estaban apareciendo en aquel entonces, relacionadas con la sostenibilidad y centradas en "garantizar las necesidades del presente sin comprometer las posibilidades de las generaciones futuras para satisfacer sus propias necesidades" (Comisión Mundial sobre Medio Ambiente y Desarrollo, citada por Zito, 2014, p. 1).

Con una orientación hacia esas corrientes se concibieron proyectos para integrar de nuevo lo natural y lo artificial, y de ahí, el río con los planes de la ciudad. Propuestas prospectivas, formuladas desde la administración y colectivos emergentes, buscaron una relación más armónica y a largo plazo de las personas con la infraestructura y el medio ambiente.

El análisis de esos momentos y fenómenos permitió hacer un recuento cronológico del río, entendido como aquel objeto guardado en la memoria de un pueblo que lo aprovechaba, una ciudad que lo olvidó y unos sectores interesados en recuperarlo a partir de nuevas transformaciones. En este contexto surgió la pregunta investigativa desde la perspectiva del diseño: ¿De qué manera los cambios en las representaciones sociales vividas por Medellín desde finales del siglo XIX hasta principios del XXI han influido en la relación de los habitantes con el río y en sus significaciones en torno a este?

La investigación planteó los siguientes objetivos:

- Indagar los mayores cambios en usos, prácticas y apropiaciones en relación con el río.

- Evidenciar cómo la relación y significación de las personas frente el afluente cambia con la concepción de ciudad que es definida según los ideales de una élite.

- Analizar cuáles son las consecuencias y repercusiones de las actividades realizadas en esta fuente hídrica en cuanto a factores ambientales, sociales e infraestructurales.

Con el fin de ampliar este panorama y obtener mayor información, se hizo un rastreo bibliográfico en el cual se encontraron aportes significativos desde la parte técnica e ingenieril en relación con el río. Sin embargo, se evidenció un vacío de conocimiento frente al fenómeno desde la visión social y antropológica. Por lo tanto, 
el interés apuntó a realizar un trabajo cuyo pilar fuera la cultura material, para estudiar así materialidades ancladas a usos, prácticas y apropiaciones que dan cuenta de representaciones sociales en la población y generan una interrelación entre sujeto, objeto y espacio. Tal enfoque condujo a identificar patrones de comportamiento y a analizar aquello que se da por sentado en la cotidianidad, para proponer entonces una postura crítica frente al papel del diseño ante planes de desarrollo urbanístico y social.

En aras de obtener resultados responsables y sólidos fue necesario contar con una base conceptual que permitiera abordar de manera crítica las formas de apropiación del río. Para dar una estructura a la investigación, la historia de este se dividió cronológicamente en tres periodos que fueron denominados como preindustrial, industrial y postindustrial. En cada etapa se manifiestan representaciones sociales, a través de los usos y prácticas de las personas en el espacio del afluente, lo cual ayudó a identificar fenómenos sociales, ambientales, infraestructurales y económicos que en distintos momentos han reconfigurado la ciudad según el interés de la élite predominante.

\section{CONCEPTOS}

\section{Representaciones sociales}

Las representaciones sociales "constituyen sistemas cognitivos en los que es posible reconocer la presencia de estereotipos, opiniones, creencias, valores y normas que suelen tener una orientación actitudinal positiva o negativa" (Araya, 2012, p. 11). En conexión con este concepto, se entendieron como orientaciones que a partir de la relación entorno-personas-objetos establecen límites y posibilidades en los usos, prácticas, apropiaciones y comportamientos de la población en relación con el río.

Se trata de un pensamiento masificado y no de ideas individuales y atomizadas en un contexto: "el sujeto no alucina las características de los objetos: comparte códigos y sentidos y los confronta en su relación con ellos" (Mandoki, 2006, p. 54). Además, "las personas o los grupos pertenecen o se constituyen en relación a los territorios que habitan, estos últimos pensados y usados según las características de los grupos de pertenencia o de sus necesidades" (Navarro, Lozano \& Rodríguez, 2008, p. 287).

Estas representaciones sociales se identificaron desde finales del siglo XIX hasta principios del XXI en los tres períodos ya señalados y que se explican a continuación.

\section{Período preindustrial}

Para esta investigación abarca desde finales del siglo XIX hasta la década del cuarenta del siglo XXI. Fue trabajado a partir de las concepciones de Granada, Mejía y Londoño (1998), Henderson (2006) y Martin (2012), con las cuales se construyó su 
caracterización. Se comprendió como un periodo en que Colombia era básicamente rural y permanecía distante de la dinámica capitalista, sin fábricas, sindicatos ni urbanización. Por lo tanto, era un país bastante desconectado del resto del mundo.

En esta época, el río no se consideraba un espacio apropiado para asentamientos humanos, debido a las crecientes y los terrenos cenagosos que se formaban a su alrededor. Las comunidades preferían establecerse en terrenos más altos, próximos a las numerosas quebradas que bañaban las laderas del valle. Algunos pobladores tenían contacto con el afluente, pues se veía como un lugar para algunas actividades de descanso, ocio y recreación

\section{Período industrial}

Fue abordado desde Fonseca (2008), Henderson (2006), Martin (2012) y Betancur (2012). Comprende desde la década del cuarenta hasta la del noventa, cuando se implementa el modelo industrial en la ciudad y se crean las que serían las fábricas más importantes tales como Coltejer, Rosellón, Reysol y la Compañía Colombiana de Tabacos. También hay un importante crecimiento demográfico debido al aumento de la migración desde el campo debido a la violencia bipartidista, familias que luego del desplazamiento, veían en la ciudad mayores oportunidades de empleo y crecimiento. En esta época se impone una idea de eficiencia asociada con la producción industrial en múltiples aspectos de la vida, pues "el nuevo prisma para ver el mundo reduce a los criterios de productividad, efectividad y ganancia, las acciones e interacciones humanas" (Granada, Mejía y Londoño, 1998, p. 22). Se acelera el ritmo urbano y se dejan de lado las costumbres de ocio antes existentes en relación con el río. Se pasa de un estado de cierta armonía hacia este a otro en que se vuelve un obstáculo. Es evitado, contaminado y se convierte en la cloaca de Medellín.

Cabe resaltar que, en este periodo, al parecer, el río Aburrá fue rebautizado "Medellín", "para inaugurar una manía, que perdura hasta hoy, de renombrar sitios y lugares para darles nuevos significados y, de este modo, sepultar el pasado" (Martin, 2012, p. 27). Esto evidencia ese deseo de la ciudad por dejar atrás su pasado "subdesarrollado", algo especialmente pedido por la élite local, lo cual ayudó a "generar una noción de modernización que implicaba la destrucción del pasado" (Martin, 2012, p. 47).

Con el transcurso de la segunda mitad del siglo XX, en Colombia se comenzó a reconocer que nada en la ciudad moderna era tan ideal como se había planeado en años previos. La pobreza y la degradación ambiental se incrementaron alarmantemente (Henderson, 2006, p. 605), la concepción productiva de la época había redefinido el vínculo con la naturaleza, donde ésta se veía únicamente como una despensa y un basurero, de donde se extraen recursos y a donde se llevan desechos. Esto se manifiesta en Medellín con la canalización del río, decisión tomada con el fin de 
ajustarlo a la estructura de la ciudad, donde permitía el paso al transporte multimodal, la industria y la vivienda y a su vez servía como cloaca de la ciudad, es decir, se convirtió un engranaje más de la gran "máquina" urbana.

\title{
Período postindustrial
}

Se trató desde Martin (2012), Gallopin (1989), Fonseca (2008) y Maya (2003) y se delimitó entre la década del noventa y principios del siglo XXI. En esta época comienzan a notarse las crisis causadas durante el período industrial y se empiezan a buscar alternativas para solucionarlas. No era la primera vez que se hablaba de estos problemas, pues desde los años cuarenta cuando se estaba planificando la ciudad, se contrataron expertos extranjeros para asesorar dicho proceso. Uno de estos fue el ingeniero y arquitecto austríaco Karl Heinrich Brunner quien hizo una propuesta para la regulación del espacio urbano, pero esta fue rechazada por los dueños de las grandes industrias:

\begin{abstract}
(...) en particular su sugerencia de prohibir el establecimiento de fábricas en una franja de 200 metros a ambos lados del río, una vez que este fuera rectificado, canalizado y dotado de carreteras. Brunner proponía garantizar que estos terrenos planos fueran utilizados para vivienda, jardines públicos, escuelas y otras funciones no industriales. Desconocía el peso del interés privado en la toma de decisiones en la ciudad y hasta qué grado estos ya habían contribuido a serios problemas con la implementación del Medellín futuro (Martin, 2012, p. 42).
\end{abstract}

Esto lo propuso con el fin de prevenir la sobreexplotación del espacio y mantener zonas naturales para equilibrar con las industriales, sin embargo, en ese momento el tema del medio ambiente era parte de un segundo plano que estaba por debajo de los intereses de crecimiento industrial, por lo que las consecuencias sólo se empezaron a reconocer como tales muchos años después y a ser conscientes de su gravedad, como subraya Fonseca (2008):

\section{El medio ambiente se convierte en problemática ambiental cuando se lo considera como problema socialmente construido, cuando se incorpora como tema en la opinión pública y se sientan las bases para discutirlo política y socialmente, cuando las consecuencias no deseadas de la modernización se hacen evidentes y son denunciadas como tales (p. 142).}

Esto ocurrió en Medellín cuando se empezó a cuestionar el modelo capitalista desbordado y a tener en cuenta realidades anteriormente pasadas por alto. Aparecieron posturas críticas y se pensó en soluciones que paulatinamente llevaron a que se pasara de ser una urbe principalmente industrial para convertirse en una inclinada a los servicios. Así, en este periodo se comienzan a considerar alternativas encami- 
nadas hacia el desarrollo sostenible, una corriente gestada en el mundo académico desde los años setenta, pero cuyos principios se empezaron a estudiar y aplicar en Medellín en los años noventa. Esta corriente apunta a construir una sociedad donde la ciudad y cuanto la rodea se entiendan de manera sistémica para garantizar un desarrollo integral y una mejor calidad de vida.

\section{Usos y prácticas}

Para estos conceptos se tomó como referencia a los autores Soja (1996), Iregui (2006) y al magister en estética Juan Diego Sanín (2006, p. 134), quien sobre el uso comenta:

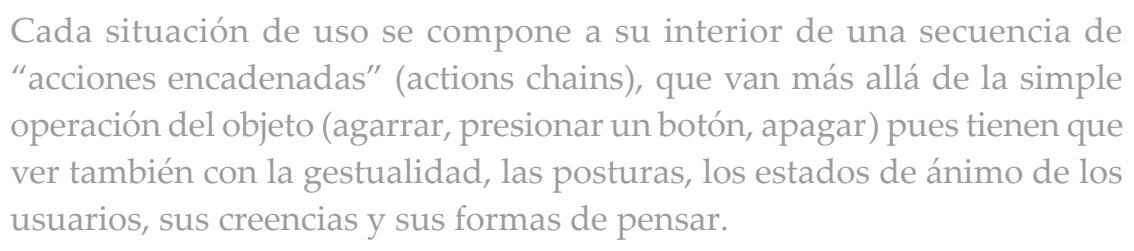

Sobre las prácticas, las define como "maneras de vinculación sociocultural entre las personas que las comparten al participar en ellas de manera similar" (Sanín, 2006, p. 11).

Estos conceptos permitieron entender la forma como las personas interactúan con el espacio según los patrones culturales de su sociedad. Igualmente, brindaron elementos para comparar el uso que la administración esperaba con el rediseño de la infraestructura, con respecto al uso real que daban las personas al espacio. Se examinaron así los conflictos o acuerdos entre ambas partes, como también si lo propuesto fue realmente utilizado o reinterpretado.

\section{Apropiaciones}

Para este concepto, nos apoyamos también en Sanín (2006) quien afirma que las apropiaciones llevan al cambio en los códigos de uso y consumo de una sociedad a través del tiempo, de modo que se convierten en un reflejo material de la cultura. Este se manifiesta como "la manera en que la gente le hace frente a esas realidades materiales impuestas, ya sea para participar abiertamente, o simplemente para ignorarlas y construir una propia" (Sanín, p. 10), esa forma de entender e interactuar con los objetos y los espacios, deja una marca tangible sobre ellos, lo cual se entiende como la apropiación.

Para ver el río no solo como un objeto sino como un espacio que se apropia, cobra peso el planteamiento del sociólogo y crítico literario francés Henri Lefebvre (2013): 


\begin{abstract}
se encuentra dominado por los 'agentes' que lo manipulan y lo vuelven monofuncional, menos se presta a la apropiación. ¿Por qué? Pues porque se sitúa fuera del tiempo vivido, tiempo diversificado y complejo experimentado por los usuarios (p. 389).
\end{abstract}

Este concepto es esencial pues para entender el papel del río es preciso analizar lo que puede decir tanto su apropiación como su "no apropiación" por parte de los ciudadanos, de modo tal que se reflejen los pensamientos y las significaciones de la población.

\title{
Espacio
}

Se consideró a Lefebvre (2013) y a Santos (2000) quien se refiere a territorio y espacio como:

\begin{abstract}
La configuración territorial está determinada por el conjunto formado por los sistemas naturales existentes en un país determinado o en un área dada y por los agregados que el hombre ha sobrepuesto a esos sistemas. La configuración territorial no es el espacio, ya que su realidad proviene de su materialidad, en tanto que el espacio reúne la materialidad y la vida que la anima (p. 54).
\end{abstract}

El espacio se entendió como el sistema natural con intervención humana, donde se desarrollan actividades que definen las características de un grupo y marcan un territorio.

\section{METODOLOGÍA}

En esta investigación de carácter cualitativo e histórico, se construyó inicialmente un marco conceptual, a continuación, se realizó una revisión documental de registros históricos para pasar luego al trabajo de campo con entrevistas y encuestas. Finalmente, se elaboró una matriz de doble entrada para sintetizar los hallazgos. La aplicación de los conceptos expuestos en el fenómeno estudiado permitió formular las reflexiones y conclusiones.

La investigación fue cualitativa ya que procuró estudiar el fenómeno desde la subjetividad y la diversidad de puntos de vista. Se utilizaron herramientas derivadas de la etnografía para conocer las opiniones de los habitantes de la ciudad en sus contextos particulares. Se empleó un instrumento cuantitativo en la tabulación de encuestas, con las cuales se pretendió hacer un paneo general sobre la percepción del río por parte de los ciudadanos. 
Como líneas guía para la recopilación de información se definieron tres variables: usos y prácticas, apropiación e intervención en el espacio, las cuales fueron analizadas en cada uno de los tres periodos identificados (preindustrial, industrial y postindustrial). La revisión de registros históricos documentales se complementó con las entrevistas y encuestas, herramientas consideradas como las más óptimas para obtener impresiones y percepciones de la gente acerca de los cambios en usos, prácticas y apropiaciones del río.

Simultáneamente con la lectura en archivos de documentos históricos que dieran cuenta de la relación entre la población y el río desde finales del siglo XIX, se realizó una prueba piloto. En esta, las herramientas para entrevistas y encuestas se aplicaron y corrigieron de manera que al ser utilizadas posteriormente respondieran de la mejor forma a las exigencias del proyecto.

En el Archivo Histórico de Medellín y la Biblioteca Pública Piloto se consultaron imágenes y relatos plasmados en documentos históricos, la información recopilada se registró en fichas iconográficas y bibliográficas. Asimismo, se realizaron cinco entrevistas, tres de ellas con expertos: Hernán Darío Gil, antropólogo de la Universidad Pontificia Bolivariana y la Universidad de Antioquia; Renier Castellanos, director de la Facultad de Historia de la Universidad Pontificia Bolivariana; y Luis Fernando González, director de la Facultad de Hábitat de la Universidad Nacional de Colombia en Medellín. Las otras dos fueron con René Panesso y Zoraida García, ciudadanos que interactuaron directamente con el río entre mediados y finales del siglo XX. También se aplicaron cien encuestas a residentes de Medellín y el Valle de Aburrá con edades entre los 19 y 70 años. La finalidad de estas fue conocer su percepción actual acerca del afluente, la manera como lo apropian e imaginan en el futuro. De esta manera se construyó una idea general sobre las representaciones sociales que tienen los habitantes de Medellín frente al río.

Con el trabajo de campo se recogió información útil y se logró lo esperado, pues se reafirmaron varias hipótesis y se obtuvieron nuevos puntos de vista relacionados con los fenómenos alrededor del río. Tras concretar los hallazgos se consignaron en una matriz de doble entrada. En esta se cruzaron los datos referentes a las variables para obtener las síntesis diacrónicas y sincrónicas que dieron pie a la formulación de las conclusiones.

El proceso realizado y los resultados investigativos se presentaron detalladamente en una monografía como trabajo de grado en Diseño Industrial. A continuación se presentan y discuten de manera sintética esos hallazgos. 


\section{RESULTADOS Y DISCUSIÓN}

\section{Un sustento utilitarista}

En la época pre-industrial los habitantes de Medellín convivían con el río en una relativa armonía, ya que junto con las quebradas, eran fuentes hídricas de sustento y recreación para los habitantes, aún no existía una tecnología que pudiera afectar esta relación significativamente. Sin embargo, el uso de del río siempre estuvo permeado por una mirada utilitarista que aseguraba el provecho para la población.

Esto lo podemos evidenciar con el autor Jasón Betancur (2012), quien en su artículo Intervención del río Medellín: La sociedad de Mejoras Públicas y la administración municipal de Medellín, 1940-1956, habla del contraste del río Medellín en cuanto a sus usos y transformaciones en el tiempo:

\section{A comienzos del siglo XX, el río Medellín era un referente paisajístico para el descanso y ocio de sus habitantes (...) esto continuó siendo así inclusive hasta los años cuarenta cuando el deterioro ocasionado por la expansión demográfica comenzaba a afectar las aguas y las riberas (Betancur, 2012, p. 246).}

Fue en esta época de mitad del siglo XX, cuando el río se comenzó a ver como un obstáculo para la construcción de viviendas, industrias y vías, pues un cauce de agua sin canalizar no era acorde con el imaginario de una ciudad urbanizada, industrializada y enfocada en la idea de progreso.

Con el fin de solucionar estas problemáticas, se dio paso a un largo proceso infraestructural cuyo comienzo fue la rectificación de la fuente hídrica. Si bien desde 1883 hubo acciones en este sentido, apenas hasta los años cuarenta la canalización estuvo en un estado de avance que permitió el asentamiento de industrias y la implementación de calzadas y vías rápidas paralelas, destinadas a atravesar la ciudad y facilitar un transporte rápido de sur a norte y viceversa. Así, las calzadas se convirtieron en un conector vial pero a la vez el río se veía como un divisor urbanístico de oriente a occidente, lo cual hizo necesaria la construcción de puentes elevados que no fueran derribados por el caudal. Entre los equipamientos que se asentaron en esta zona, se encuentran los que luego serían los más importantes y representativos de la ciudad a nivel industrial, comercial, educativo y de entretenimiento. Sólo después de estas 
adecuaciones, el río tuvo un papel significativo para la ciudad moderna, desde la perspectiva que permitía la expansión urbana y el crecimiento económico, “el arreglo del río Medellín, se consideraba la columna vertebral del desarrollo urbano" (Betancur, 2012, p. 251).

Con la llegada de las tecnologías industriales, el afán por el desarrollo y la búsqueda de progreso, hubo una transformación. La producción se convirtió en la prioridad y esto se vio reflejado en las materialidades, las representaciones sociales y el estilo de vida de los habitantes de Medellín. Surgió una idea de "productividad" aplicada a todos los aspectos de la vida cotidiana, que conllevó a que para una buena parte de los residentes, fuera necesario responder a una mayor cantidad de actividades en el menor tiempo posible. Estos cambios se pueden evidenciar en materia de transporte, donde a finales del siglo XIX se utilizaban balsas de madera para navegar y transportar productos por el río, pero cuando llegaron los vehículos automotores, se convirtieron en los protagonistas al ser consecuentes con la eficiencia que se requería en aquel entonces. Las vías a lo largo del río Medellín, el ferrocarril (1904) y el tranvía eléctrico (1921), impulsaron un desarrollo de la urbe hacia el norte y el sur del centro histórico (Martin, 2012). El ritmo de la ciudad se aceleró, las autopistas paralelas al río se convirtieron en barreras que bloquearon el contacto con los habitantes y se pasó de una interacción directa con él a pasar de largo por sus costados.

El crecimiento económico registrado desde finales del siglo XIX debido a estas transformaciones influyó en la configuración del espacio. La ciudad se estratificó y fragmentó entre sur y norte, aparecieron fronteras entre sectores con características sociales muy distintas y marcadas, al punto de generarse conflictos entre ellos, fenómeno indicativo de un "patrón excluyente de desarrollo" (Martin, 2012, p. 48). Esto hizo parecer que se conformaran varias ciudades dentro de la misma, y se podría decir que uno de los pocos vínculos que existen entre ellas sea la idea de que el río, mientras proporcione algún beneficio, es tenido en cuenta, sin embargo cuando empieza a verse como un problema y debe invertirse en la recuperación de éste o de los daños que ha causado, se considera obsoleto.

La idea del río como algo ajeno, arraigada en la mente de los ciudadanos, puede considerarse un patrón que conllevó a esos comportamientos u orientadores sociales. Estos, a su vez, condicionaron y afectaron las representaciones sociales frente al afluente.

\section{La cloaca}

Según lo expresado por los expertos entrevistados, esa concepción del río como algo ajeno y a veces hasta "invisible" responde a unas representaciones sociales, algunas de las cuales estaban establecidas incluso desde épocas precolombinas, tiempo en que los nativos del valle se asentaban en las partes altas de las quebradas al ser lugares seguros donde podían evitar las peligrosas crecientes del río. En realidad, el afluente 
nunca tuvo un papel tan protagónico como el de sus múltiples quebradas tributarias, unas 1200 aproximadamente. Entre ellas por ejemplo, la quebrada Santa Elena fue de gran importancia, pues en torno a ella se configuró la villa y se consideró el norte de la ciudad durante la primera parte del siglo XX. De hecho, su desembocadura en el río se entendía como la espalda de Medellín y entre mayor cercanía a éste, mayor era el desagrado que sentían algunos habitantes por esa zona, mientras que otros, veían su caudal irregular como un lugar de esparcimiento y disfrute.

En esta época, los mismos pobladores eran quienes definían un sentido, una función para esas fuentes hídricas y se apropiaban de ellas. Sin embargo, a principios del siglo XX, la administración municipal se empezó a imponer sobre los ciudadanos y a convencerlos de un imaginario de progreso que se consideraba iba a ser lo mejor para el crecimiento de la ciudad y que favorecería económicamente a la élite. Al existir una preocupación por las zonas pantanosas y húmedas próximas al río, la cuales se veían como obstáculos para el crecimiento de sectores residenciales e industriales y focos de enfermedades, al discurso de progreso se sumó el de la higiene (Henderson, 2006) para convertirse en los argumentos centrales que se emplearon en la tarea de convencer a la población sobre la urgencia de la canalización.

Con estas ideas, la apropiación del río cambió. Tras su canalización fue aislado, su sentido se fragmentó y quedó indefinido para los ciudadanos. El sector productivo pasó a definir su función, donde al estrechar su cauce se pudo establecer en sus costados y además utilizarlo como vertedero de desechos. Como para el resto de los ciudadanos ya no tenía una función clara, empezaron a aparecer otros usos. No solo se convirtió en basurero sino que bajo los puentes y en los desagües se establecieron personas desplazadas por la violencia y habitantes de la calle, quienes desarrollaron su vida cotidiana en este lugar. Se vio también como el lugar propicio para arrojar cadáveres, práctica derivada del conflicto bipartidista de aquel entonces, por lo que en el río se vio reflejado un problema no solo ambiental sino también social. El resto de la población pasó simplemente a ignorar el afluente, porque ya no tenía ninguna función para ellos.

Estos usos que no eran los más favorables, si bien imposibilitaron unas prácticas de ocio realizadas por algunos habitantes, estos no se sintieron violentados, puesto que esas consecuencias eran vistas como efectos secundarios y poco relevantes a comparación de todo lo bueno que traería la canalización para el progreso de la ciudad. Estas transformaciones se aceptaron sin considerar los efectos que traerían, lo cual significó el inicio de un camino seguro hacia la crisis futura. "El ideal de progreso se desdibuja en la medida en que éste significa también su contrario: pobreza y degradación ambiental" (Fonseca, 2008: 143). 
No existía un sentido de pertenencia hacia el río, lo cual desencadenó todos estos sucesos que contribuyeron a su deterioro. A partir de ese momento el afluente se convirtió en referente de inseguridad, contaminación y violencia, ya que no era considerado un elemento sagrado o protagónico en la ciudad. Así, se puede ver que su importancia ha variado de acuerdo con las condiciones históricas y la interpretación del desarrollo en cada época.

A la vanguardia con el río

A ese ritmo Medellín entró en crisis, como se sugirió en el informe del Foro Internacional Ciudadanos transformando ciudad, realizado en 2009 en el Centro de Convenciones y Exposiciones Plaza Mayor de la capital antioqueña:

\footnotetext{
El modelo de gestión para el desarrollo centrado en lo económico y sustentado en la individualidad, acrecentó las desigualdades sociales y profundizó la exclusión de grandes sectores de la población, intensificando la pobreza y reduciendo los espacios de participación (...) el grupo de países más grandes del mundo, G-20, plantea, entre otros temas urgentes, abordar caminos de desarrollo incluyentes y sostenibles para todos; y finalmente, la asamblea del BID realizada en Medellín en 2009 enfatizó en las economías alternativas como motor de desarrollo y destacó, en casi todos los campos, la desigualdad como principal estigma de las zonas geográficas menos equitativas del mundo (Departamento Administrativo de Planeación Institución Universitaria Esumer, 2009, p. 13).
}

El río fue afectado por esa crisis y con el paso del tiempo su deterioro no pudo seguir pasando desapercibido. La degradación comenzó a ser mal vista ya que estas ideas de sostenibilidad empezaron a tenerse en cuenta. Medellín no podía quedarse atrás de los nuevos modelos ni mostrarse indiferente frente a las preocupaciones ambientales. Era preciso acoplarse a estas y proyectarse como una ciudad acorde a las tendencias mundiales, pues esto significaba acercarse al ideal de progreso del periodo postindustrial. 
Una respuesta local para la aplicación de esos modelos fue el Instituto Mi Río, creado en 1992. Entre sus objetivos se encontraba la disminución de los volúmenes de polución que llegaban a las fuentes hídricas y el fomento de una nueva cultura ciudadana basada en el respeto por el otro y el medio ambiente (El Tiempo, 1999). Se buscaba que el río dejara de ser asociado con contaminación y violencia y se reintegrara a la ciudad desde el urbanismo. La estrategia no tuvo la acogida esperada ni entre los ciudadanos, quienes siguieron indiferentes frente a la problemática, ni entre el sector industrial, de nuevo poco interesado en programas de recuperación que pudieran afectar sus actividades económicas.

Este primer intento fracasó y fue una muestra de que se debe preparar mejor el terreno para lograr proyectos exitosos. Era preciso transmitir un discurso coherente con antelación, construido con bases sólidas desde un estudio a conciencia de la situación local real y no sólo importar esquemas y soluciones del exterior. La falta de planificación ocasionó que no se desarrollaran planes contundentes desde lo autóctono, lo cual debilitó aún más el sentido de pertenencia y la valoración por lo propio.

A pesar de este proyecto fallido, desde entonces y hasta principios del siglo XXI, se continuó con la iniciativa de formular e implementar diversos proyectos que apuntaban a la sostenibilidad, para evitar crear una imagen de Medellín como ciudad quedada en cuanto a tendencias. Constantemente hay un interés por generar protagonismo e impacto al hacer parte de la ola verde con una planeación urbana que integre lo natural y lo artificial. En los años más recientes (2014 - 2015), se destaca el proyecto Parques del Rio, el cual es presentado por la administración municipal como la solución perfecta, pues este megaproyecto va de acuerdo con la recuperación de las fuentes hídricas, genera crecimiento en la industria inmobiliaria y representa una conveniencia económica y política. Para hacer esto posible, se busca generar un sentimiento de apropiación del río entre los ciudadanos, donde se vea el afluente como algo necesario y valioso en la cotidianidad de los habitantes (Empresa de Desarrollo Urbano, 2015) Esta concepción, si bien es compleja de implantar, se busca que sea acogida ya que sólo de esta manera el proyecto puede funcionar. 
Se tiene la idea es que si propuestas semejantes dieron resultado en otros países desarrollados, lo mismo debe hacerse aquí. Al considerar esta proyección y el contexto de Medellín, surge una pregunta: ¿hasta qué punto es válida la inversión en este tipo de obras en una ciudad con un sinnúmero de problemáticas sociales, tales como pobreza, desigualdad social y desempleo? Esto sumado a la indiferencia que se percibe entre la mayoría de los habitantes hacia el río, constituye la principal inquietud de muchos ciudadanos y uno de los puntos de mayor crítica.

Al parecer, simplemente se trata de acoplarse y dejarse llevar por una tendencia sin tener bases, representaciones sociales sólidas ni ideales críticos respecto a la realidad. De repente, parece como si surgiera una culpa generalizada y repentina hacia costumbres que hasta hace poco eran bien vistas, como arrojar indiscriminadamente desechos a las aguas. Han surgido miles de dolientes para dignificar una causa que se creía perdida. Ahora, el sinónimo de progreso es la sostenibilidad, y parece que la ruta es seguir los proyectos implementados en potencias mundiales para mantener el reconocimiento como la "ciudad más innovadora".

\section{Quien no conoce su historia está condenado a repetirla.}

Con el paso del tiempo la "novedosa Medellín" se destruye, construye y reconstruye continuamente. No se actúa con la intención de dejar un legado, sino de suplir las exigencias del momento. No se conserva ni se valora el pasado y tampoco interesa hacerlo, se tolera la destrucción de todo lo que no esté en consonancia con lo que se quiere proyectar. Se podría decir entonces que Medellín es una ciudad sin memoria.

Esto se refleja en los ideales de los habitantes, cuyas representaciones sociales son cíclicas: a finales del siglo XIX, el río era para algunos un punto de encuentro y para otros un lugar a evitar; en el siglo XX, con la industrialización, pasó a ser un divisor urbanístico; $\mathrm{y}$ ahora, desde finales del siglo XX y principios del XXI se busca volver a la idea inicial donde era un referente de integración social, para generar un equilibrio y armonía entre el entorno artificial y el natural.

Cuando no existe una planificación sólida de ciudad y se va de un lado a otro, se derriban muchas construcciones materiales que fueron representativas en otras épocas, sin importar el tiempo que lleve su construcción, su uso, si han perdurado mucho o poco, o si significa o no algo para los ciudadanos. Pocos han sido restaurados o se les ha reasignado la función para la que fueron creados. Se pasa por encima de estos íconos porque la prioridad es lo nuevo. Se huye del pasado ya que se le desconoce, y a lo desconocido se le tiene miedo. 
Así también ha sucedido con el río de una manera más abstracta, pues la destrucción de este se relaciona con el hecho de interrumpir su naturaleza y transformarlo en un canal. Ese abandono puede verse también desde el momento en el que aumenta la contaminación, lo cual genera su deterioro y no se le da importancia o valor a esta fuente hídrica. Ha llegado un momento en que se pretende recuperarlo, surge la duda de si ¿será con fines hacia la novedad, a seguir las tendencias?, ¿perderán fuerza estas iniciativas así como ocurrió años atrás con otros proyectos? ¿Volverá a ser ignorado?

En Medellín no hay una cultura de conservación histórica. Se cree más simple borrar el pasado y reconstruir con una proyección a lo actual, que restaurar elementos supuestamente irrecuperables y ajenos al boom del momento, esto se ve como una pérdida de tiempo y no como una inversión histórica. El interés es mostrarse como una ciudad fresca con una arquitectura deslumbrante, que esté siempre a la vanguardia.

En el río se puede ver reflejado el pensamiento de los ciudadanos: una mirada utilitarista que funciona como patrón de decisión frente a los elementos urbanos. Esas representaciones sociales cíclicas, muestran que se quiere volver a unas supuestas prácticas de apropiación del pasado, que quizá nunca han estado interiorizadas en la mente de los medellinenses. Parece que se trata simplemente de romantizar unas prácticas que hubo en el río para dar impulso a grandes proyectos de mucha inversión, pero que nunca estuvieron realmente arraigadas en la mente de los habitantes. 
El río nunca ha sido realmente importante o no se ha buscado hacerlo visible. El protagonismo en realidad ha sido de los megaproyectos e infraestructuras de gran magnitud que se han desarrollado a su alrededor, sean o no para solucionar las problemáticas directas del afluente. Las estrategias no están precisamente enfocadas en su recuperación sino en hacerlo notar como un atractivo en ciertos momentos para difundir la idea de crecimiento urbano.

Se puede notar que en proyectos como Parques del Río, aunque desde su nombre el foco es el río Medellín, no se ha fortalecido tanto la recuperación del mismo, sino que se ha promovido con mayor fuerza los beneficios que traerá el proyecto en cuanto a movilidad e integración social. El río se presenta como un escenario decorativo y la excusa para que la administración actual muestre un proyecto urbanístico bandera con el cual ser recordada, además de tener implícitos intereses económicos y políticos. No en vano se escoge este tramo del río (desde la calle 33 hasta San Juan), pues es donde se encuentran algunos de los equipamientos más importantes de la ciudad. Se busca valorizar el terreno y conectar ambos costados para conformar un epicentro administrativo, de servicios y turístico, lo cual puede generar mayor crecimiento económico. Este proyecto pretende responder a las demandas y solucionar algunas problemáticas de la época post-industrial en la ciudad, siguiendo la idea de progreso. ¿Podría entonces decirse que se trata de la versión post-industrial del proyecto de canalización?.

En el desarrollo de estos proyectos tienen cabida varias disciplinas y entre ellas es válido incluir al diseño. Desde la formación académica un diseñador debe tener muy claro el contexto al que dirige su propuesta, los tipos de usuario y las condiciones sociales, económicas y ambientales de cada entorno. De este modo, puede aportar sus conocimientos desde la indagación y la síntesis de información, interpretando antes de formular, producir ideas, objetos y espacios desde una mirada crítica en que las materialidades surgen a partir de los imaginarios o las representaciones sociales de las personas en un contexto específico. Así, busca resolver fenómenos responsablemente, con respuestas tangibles e intangibles.

El diseño debe centrarse en el usuario, tener en cuenta los usos, las prácticas y apropiaciones que se dan en el espacio y en interacción con los objetos, para garantizar el éxito de la propuesta. En tal sentido, esta investigación no solo permitió conocer un poco más sobre la historia de Medellín a través de su río, sino también evidenciar a la disciplina como parte fundamental en la intervención y creación de ciudad, aunque apenas se le empiece a tener en cuenta en este campo. Recientemente se está incluyendo en el proceso de planificación de grandes proyectos y es el momento de que tenga voz y voto. 
De la investigación también surgieron reflexiones relacionadas con el papel del río en la memoria de la ciudad, pues ha estado presente en los tres momentos planteados y ha sido testigo silencioso de la "invisibilización" de otros afluentes, incluso de la quebrada Santa Elena, cuyo papel fue más importante. Frente a tal realidad, ¿cabe pensar que no puede ser "invisibilizado" en su totalidad, así esto se haya intentado? Por un motivo u otro no se le ha tapado por completo, siempre ha estado ahí, sonando, oliendo, llamando la atención, así parezca débil. No ha desaparecido completamente del paisaje y por lo tanto, tampoco de la memoria, como tratando de recordar algo. Sigue siendo ese vínculo con el pasado que, aunque todos no conozcan, se conserva como una cicatriz imborrable de la cual no se recuerda la causa.

Finalmente, llegamos a la conclusión de que es posible reconstruir la historia de Medellín a partir de su relación con el río, ya que todos los cambios que se han visto en la ciudad se ven de alguna manera reflejados en el afluente. A través de él, se pueden evidenciar las representaciones sociales de lo que era una villa y lo que ahora es "la ciudad más innovadora del mundo". El río es una analogía de la ciudad, una ciudad que al intentar "invisibilizarlo", ha perdido su memoria. Aquí, el río es protagonista por instantes y la memoria de Medellín solo juega un papel importante en ciertos momentos, cuando puede aprovecharse para perseguir el progreso de la época. 


\section{REFERENCIAS BIBLIOGRÁFICAS}

Araya, S. (2012). Las representaciones sociales: ejes teóricos para su discusión. San José, Costa Rica: Asdi.

Betancur, J. (2012). Intervención del río Medellín: la Sociedad de Mejoras Públicas y la administración municipal de Medellín, 1940 - 1959. Historelo, 4(8), 239-274.

Comisión Mundial sobre el Medio Ambiente y Desarrollo. (s.f.). Nuestro Futuro Común, de Excmo Ayuntamiento de Toledo. Recuperado el 12 de Marzo de 2014 Nuestro futuro común: http://www.ayto toledo.org/medioambiente/a21/BRUNDTLAND.pdf

Departamento Administrativo de Planeación - Institución Universitaria Esumer. (2009). Foro Internacional Ciudadanos Transformando Ciudad. Experiencias de Planeación Local y Presupuesto Participativo. Medellín: Institución Universitaria Esumer.

El Tiempo. (1999, septiembre 30). Mi Río es de todos. Recuperado de http://www.eltiempo.com/archivo/ documento/MAM-921433

Empresa de Desarrollo Urbano. (2015). Parque del Río Medellín. Recuperado el 8 de agosto de 2015, de http://www.edu.gov.co/index.php/proyectos/parque-vial-del-rio.html

Fonseca, F. (2008). Procesos de ruptura y continuidad entre naturaleza y sociedad en la ciudad moderna. Papers, (88), 141-151.

Gallopín, G. (2003). Sostenibilidad y desarrollo Sostenible: un enfoque sistémico. Santiago de Chile: Naciones Unidas.

Granada, A., Mejía, H. \& Londoño, C. E. (1998). El devenir de América Latina. Pensamiento Humanista, (4), 19-37.

Henderson, J. (2006). La modernización en Colombia: los años de Laureano Gómez, 1889-1995. Medellín: Universidad de Antioquia.

Iregui, J (2006) Los espacios del espacio público. Recuperado el 8 de Agosto de 2015 de http://www.sistemamid.com/panel/uploads/biblioteca/7097/7098/7110/7112/82827.pdf

Lefebvre, H. (2013). La producción del espacio. Madrid: Capitán Swing Libros.

Mandoki, K. (2006). Estética cotidiana y juegos de la cultura: prosaica. México: Siglo XXI.

Martin, G. (2012). Medellín, tragedia y resurrección: mafia, ciudad y Estado 1975 - 2012. Bogotá: Planeta Colombiana.

Maya, A. Á. (2003). La Diosa Némesis: Desarrollo Sostenible o Cambio Cultural (Vol. 2). Cali: Vicerrectoria de Investigaciones y Desarrollo Tecnológico.

Navarro, O., Lozano, N. \& Rodríguez, U. (2008). Mapas mentales: la representación cognitiva del espacio como método de investigación social. En P. Páramo (ed.). La investigación en ciencias sociales: técnicas de recolección de información (pp. 285 - 299). Bogotá: Universidad Piloto de Colombia.

Sanín, J. (2006). Estéticas del consumo. Medellín: Universidad Pontificia Bolivariana.

Santos, M. (2000). La Naturaleza del Espacio. Barcelona: Ariel.

Soja, E. (1996). La trialéctica de la espacialidad. En Soja, E. Tercer espacio (págs. 1-11) 